УДК [004.382.76+004.738.5]:378.147

DOI: https://doi.org/10.35387/od.2(18).2020.106-115

Модло Євгеній Олександрович - кандидат педагогічних наук, завідувач кафредри електричної інженерії та автоматизації Державного університету економіки і технологій, м. Кривий Ріг

ORCID iD: https://orcid.org/0000-0003-2037-1557

E-mail: eugenemodlo@gmail.com

Семеріков Сергій Олексійович - доктор педагогічних наук, профессор, провідний науковий співробітник відділу хмаро орієнтованих систем інфоорматизації освіти Інституту інфрормаційних технологій і засобів навчання НАПН України

ORCID iD: https://orcid.org/0000-0003-0789-0272

E-mail:semerikov@gmail.com

Маркова Оксана Миколаївна - кандидат педагогічних наук, старший викладач кафедри комп'ютерних систем та мереж Криворізького національного університету

ORCID iD: https://orcid.org/0000-0002-5236-6640

E-mail:markova@mathinfo.ccjournals.eu

\title{
МОБІЛЬНІ ІНТЕРНЕТ-ПРИСТРОЇ ЯК ЗАСІБ ФОРМУВАННЯ ЗАГАЛЬНОПРОФЕСІЙНОЇ КОМПЕТЕНТНОСТІ БАКАЛАВРА ЕЛЕКТРОМЕХАНІКИ В МОДЕЛЮВАННІ ТЕХНІЧНИХ ОБ'ЄКТІВ
}

\begin{abstract}
Анотація. У статті розглянуто складові методики використання мобільних інтернет-пристроїв як засобу формування загальнопрофесійної складової компетентності бакалавра електромеханіки в моделюванні технічних об'єктів: застосування різних способів подання моделей; розв'язання профресійних задач засобами IКT; компетентності в електричних машинах та критичного мислення. На змісті навчання навчальних дисциплін «Вища математика», «Теорія автоматичного управління», «Моделювання електромеханічних систем», "Електричні машини» розкрито особливості використання Scilab, SageCell, Google Sheets, Xcos on Cloud для фрормування загальнопрофресійної компетентності бакалавра електромеханіки в моделюванні технічних об'єктів. Зроблено висновок про доцільність використання наступного програмного забезпечення мобільних інтернет-пристроїв: хмаро орієнтованих табличних процесорів як засобів моделювання (включно із нейромережевим); систем візуального моделювання як засобів структурного моделювання технічних об'єктів; мобільних комп'ютерних математичних системи, що використовується на всіх етапах моделювання; мобільних комунікаційних засобів для організації спільної діяльності з моделювання. Виходячи зі змісту
\end{abstract}


компетенції із застосування різних способів подання моделей, ії формування та розвиток відбувається протягом усієї профресійної підготовки бакалавра електромеханіки, тому виокремлювати провідні для цього процесу навчальні дисципліни недоцільно. Дана компетенція $\epsilon$ загальнопрофесійною складовою компетентності бакалавра електромеханіки в моделюванні технічних об'єктів. Важливою складовою компетенції із застосування різних способів подання моделей $\epsilon$ формування здатності до добору адекватних способу подання моделі засобів комп'ютерного моделювання. Одним із традиційних для навчання моделювання засобів ІКТ є системи комп'ютерної математики.

Ключові слова: мобільні інтернет-пристрої; бакалаври електромеханіки; моделювання технічних об'єктів; компетентності бакалавра електромеханіки; методика використання мобільних інтернет-пристроїв; навчання бакалаврів електромеханіки.

Modlo Yevhenii - PhD (ICT Education), Head of Department of Electrical Engineering and Automation, State University of Economics and Technology, Kryvyi Rih

ORCID iD: $h$ ttps://orcid.org/0000-0003-2037-1557

E-mail: eugenemodlo@gmail.com

Semerikov Serhiy - Doctor of Pedagogical Sciences (CS Education), Full Professor, Leading Researcher of the Department of Cloud-Oriented Systems of Education Informatization of the Institute of Information Technologies and Learning Tools of the NAES of Ukraine

ORCID iD: https://orcid.org/0000-0003-0789-0272

E-mail:semerikov@gmail.com

Markova Oksana - Candidate of Pedagogical Sciences (ICT Education), Senior Lecturer of the Department of Computer Systems and Networks of the Kryvyi Rih National University

ORCID iD: https://orcid.org/0000-0002-5236-6640

E-mail:markova@mathinfo.ccjournals.eu

\section{MOBILE INTERNET DEVICES AS A TOOL OF FORMATION OF THE GENERAL PROFESSIONAL COMPETENCE OF ELECTROMECHANICS BACHELOR IN TECHNICAL OBJECTS MODELING}

Abstract. The article describes the components of methods of using mobile Internet devices in the formation of the general professional competence of an electromechanics bachelor in technical objects modeling: using various methods of representing models; solving professional problems using ICT; competence in electric machines and critical thinking. On the content of teaching academic disciplines "Higher mathematics», "Automatic control 
theory», "Modeling of electromechanical systems», "Electrical machines» there are disclosed the features of use of Scilab, SageCell, Google Sheets, Xcos on Cloud for forming the general professional competence of the electromechanics bachelor in technical objects modeling. According to the author, it is advisable to use the following software for mobile Internet devices: a cloud oriented table processors as modeling tools (including neural networks), a visual modeling systems as a means of structural modeling of technical objects; a mobile computer mathematical system used at all stages of modeling; a mobile communication tools for organizing joint modeling activities. Based on the content of competence of the application of different methods of presenting models, its formation and development occurs throughout the professional training of the electromechanics bachelor, so it is impractical to single out the leading disciplines for this process. This competence is a general professional component of the competence of the electromechanics bachelor in technical objects modeling. An important component of the competence in the application of different methods of model representation is the formation of the ability to select adequate methods of model representation of computer modeling tools. One of the traditional ways to teach ICT modeling is computer mathematics.

Key words: mobile Internet devices; electromechanics bachelors; technical objects modeling; bachelor's degree in electromechanics; methods of using mobile Internet devices; bachelor's degree in electromechanics.

Постановка проблеми, iï актуальність. Модернізація професійної підготовки фахівців 3 мехатроніки у технологічних університетах України (Modlo, Semerikov \& Shmeltzer, 2018) на основі забезпечення балансу між фрундаментальною (Modlo et al., 2020) та технологічною складовою процесу підготовки зумовлює необхідність пошуку засобів IKT навчання (Modlo et al., 2019), що не лише надаватимуть можливість активного експериментування у будь-який час та будь-якому місці, а й підтримуватимуть розвиток професійно важливих якостей майбутнього інженера-електромеханіка, серед яких чільне місце посідає компетентність в моделюванні технічних об'єктів. Сьогодні такими універсальними засобами навчання $є$ мобільні інтернет пристрої (Kanivets et al., 2020; Rassovytska \& Striuk, 2017; Tkachuk, Shchokin \& Tron, 2018).

У нашій публікації візуалізовано окремі результати дослідження, розпочатого у статтях (Modlo et al., 2019) та (Modlo et al., 2020), що має на меті розроблення методики використання мобільних інтернет-пристроїв як засобу формування компетентності бакалавра електромеханіки в моделюванні технічних об'єктів.

Аналіз останніх досліджень і публікацій. І.М. Соболь у (Соболь, 1968) пропонує алгоритм наближеного обчислення визначеного інтегралу методом Монте-Карло, зауважуючи, що «на практиці [однократні] інтеграли ... методом Монте-Карло не обчислюють: для цього $є$ більш точні методі квадратурні фрормули. Однак при переході до багатократних інтегралів стан 
речей змінюється: квадратурні формули стають дуже складними, а метод Монте-Карло залишається майже без змін» (Соболь, 1968, с. 52). Тому, за висновком ЮНЕСКО, застосування мобільних технологій надає можливість суттєвого розширення та покращення можливостей для навчання, зокрема, у закладах вищої освіти. Яскравим прикладом використання мобільних пристроїв у навчанні в Колумбії є проєкт BlueGénesis, розпочатий у 2006 р. і спрямований на студентів, із мобільних пристроїв яких утруднений або неможливий доступ до Інтернет. На відміну від BlueGénesis, проєкт Aprendizaje Móvil, розпочатий у 2010 р., зосереджується саме на використанні мобільних інтернет-пристроїв студентами першого курсу для доступу до навчальних ресурсів, розміщених на різних платформах.

Одним із традиційних для навчання моделювання засобів ІКТ $€$ системи комп'ютерної математики. Так, у (Модло, 2015) вказано на доцільність застосування їх разом із системами підтримки навчання бакалаврів електромеханіки моделювання технічних об'єктів, такими як система Moodle, доповненої розробленим фільтром SageCell (Модло \& Семеріков, 2014). Вказаний фрільтр здатен реалізовувати чисельне розв'язування систем диференціальних рівнянь, що описують математичні моделі, безпосередньо у системі підтримки навчання.

На поточний момент найбільшу експертну оцінку має середовище Scilab, переваги використання якого у 2011 р. визнало Міністерство національної освіти, вищої освіти і науки Франції, надавши Scilab знак визнання його педагогічної значущості для навчання математики «Reconnu d'Intérêt Pédagogique» (Scilab is recognized as having educational value by the French Department of Education, 2011).

Завдяки використанню унікальних переваг мобільних пристроїв вони доповнюють наявні ресурси (підручники, інфраструктуру, обладнання, засоби підготовки та інформаційне забезпечення).

Мета статті - добір та обґрунтування засобів мобільних Інтернет пристроїв, використання яких сприяє формуванню загальнопрофесійної компетентності бакалавра електромеханіки в моделюванні технічних об'єктів.

Виклад основного матеріалу дослідження. Формування такої загальнопрофесійної складової компетентності бакалавра електромеханіки в моделюванні технічних об'єктів, як компетенція із застосування різних способів подання моделей, передбачає набуття знань та умінь побудови комп'ютерних математичних та імітаційних моделей, їх алгоритмічного та структурного опису, добору адекватних способу подання засобів комп'ютерного моделювання. Виходячи зі змісту компетенції, її формування та розвиток відбувається упродовж усієї професійної підготовки бакалавра електромеханіки, тому виокремлювати провідні для цього процесу навчальні дисципліни недоцільно. Так, у процесі навчання дисципліни «Обчислювальна техніка та програмування» можна розв'язати розглянуту у модулі 9 «Визначений та невласні інтеграли» навчальної 
дисципліни «Вища математика» задачу чисельного інтегрування у іншій постановці: замість табличного подання функції застосувати аналітичне, а замість інтерполяційних формул - стохастичний підхід на основі методу Монте-Карло. При цьому використовується перша теорема про середнє значення визначеного інтегралу, згідно якої для криволінійної трапеції, площа якої дорівнює значенню визначеного інтегралу, існує рівний за площею прямокутник, довжина якого дорівнює відрізку інтегрування, а висота - середньому значенню підінтегральної функції на цьому відрізку.

Першу реалізацію виконаємо у середовищі моделювання SageCell (Popel, Shokalyuk \& Shyshkina, 2017), за допомогою якого значення інтегралу обчислювалось детерміністичними методами. Іншу реалізацію спрямуємо на проведення студентами якомога більшої кількості експериментів для з'ясування того факту, що за однієї й тієї ж кількості експериментів результати моделювання можуть суттєво відрізнятися.

Обговорення двох реалізації однієї моделі дає можливість зробити висновки як про правильність реалізації, так й про доцільність використання обраного засобу моделювання. Так, при використанні електронних таблиць збільшення кількості експериментів можливе лише шляхом додавання нових рядків, проте будь-які зміни на робочому аркуші приводять для генерування нових випадкових чисел - замість уточнення результатів попереднього експерименту студент проводить новий експеримент.

Важливою складовою компетенції із застосування різних способів подання моделей $є$ формування здатності до добору адекватних способу подання моделі засобів комп'ютерного моделювання.

Однак використання тільки систем комп'ютерної математики (навіть таких потужних, як SageMath (Sage Cell Server)) для навчання моделювання технічних об'єктів бакалаврів електромеханіки є недостатнім, оскільки при синтезі та обчисленні моделей систем керування, елементів електроприводу та ін. використовуються насамперед засоби візуального моделювання, що надають можливість будувати динамічні моделі (дискретні, неперервні та моделі систем із розривами). Це зумовлює необхідність та доцільність об'єднання традиційних систем комп'ютерної математики зі спеціалізованими бібліотеками для моделювання технічних об'єктів у оболонки для візуального конструювання моделей. При цьому вибір середовища для моделювання має ураховувати специфіку майбутньої професійної діяльності, якою для бакалаврів електромеханіки $є$ синтез відповідних технічних об'єктів - електромеханічних систем.

Опанування моделювання технічних об'єктів забезпечує теоретичне та практичне наповнення фундаментальної, загально- та спеціалізовано-професійної підготовки бакалавра електромеханіки. У зв'язку з цим бажано, щоб середовище для їх моделювання надавало користувачеві доступ не лише до традиційних бібліотек моделювання неперервних та дискретних динамічних систем, а й до бібліотек для електричних машин та силових перетворювачів. Крім того, для досягнення 
цілі мобільності навчання середовище моделювання повинно мати високий рівень кросплатформенності (зокрема, доступ через Web-інтерфейс) та бути вільно поширюваним.

Згідно (Scilab, 2019), Scilab - пакет наукових програм для чисельних обчислень, що надає потужне відкрите середовище для розрахунків, схожу на Matlab мову і набір функцій для математичних, інженерних і наукових розрахунків. Пакет підходить для професійного застосування і використання у ЗВО, надаючи інструменти для різноманітних обчислень: від візуалізації, моделювання та інтерполяції до диференціальних рівнянь та математичної статистики. Підтримується виконання сценаріїв, написаних для Matlab.

Стандартний Web-інтерфейс до Scilab, що пропонується Cloud Scilab (Web application - Scilab.io, 2016), не передбачає інтерфейсу користувача, подібного до повнофункціональної версії - надається лише можливість розміщення створених користувачем моделей із Webінтерфейсом шляхом створення та оприлюднення інтерактивних документів, програмна частина яких виконується на боці сервера, що економить ресурси мобільного інтернет-пристрою. Це надає ряд переваг: централізація даних, що використовуються та створюються користувацькою програмою; відсутність необхідності встановлення програмного забезпечення на боці клієнта; приховування коду від кінцевих користувачів (як складова захисту інтелектуальної власності); централізація коду Scilab для забезпечення ефективної роботи програм.

Програми, розгорнуті в Scilab Cloud, описуються мовою Scilab (як алгоритми, так й інтерфейс користувача). Це дозволяє створювати програми з візуальним інтерфейсом як для розгортання у хмарі (працюють y Scilab Cloud 3 відображенням через веб-браузер), так й традиційного виконання (запуск із Scilab на комп'ютері користувача). Незважаючи на високий рівень мобільності, використання Cloud Scilab супроводжується рядом проблем: розгортання програм доступно лише за наявності адміністративних привілеїв (потребує додаткової платні постачальнику хмарних послуг); інтерфейс надається лише для користувацьких моделей, а не до всього інтерфейсу Scilab. За функціональністю даний сервіс $€$ подібним до Wolfram Demonstrations Project, проте, на відміну від останнього, оприлюднювати демонстрації можуть усі користувачі, а не лише адміністратори сервісу, що відповідає моделі поширення документів у CoCalc (Markova, Semerikov \& Popel, 2018). Проте Scilab Cloud не надає доступ до модуля Хcos.

Зазначимо, що Xcos $€$ доповненням до Scilab, що надає можливості синтезу математичних моделей в галузі механіки, гідравліки, електроніки та електромеханіки. Дане середовище візуального моделювання призначене для розв'язання задач динамічного моделювання систем, процесів, пристроїв, а також тестування та аналізу цих систем. При цьому об'єкт, що моделюється (система, пристрій, 
процес), подається графічно блок-схемою, що включає блоки елементів системи і зв'язки між ними.

Найбільш вагомими критеріями, що зумовили вибір Scilab як засобу навчання моделювання технічних об'єктів бакалаврів електромеханіки, $€$ наявність бібліотек для моделювання неперервних систем (5 балів), наявність бібліотек для моделювання дискретних систем (5 балів) та наявність Web-інтерфейсу (3 бали). Останнє надає можливість його використання на мобільних інтернет-пристроях.

Cервіс Xcos on Cloud розв'язує цю проблему, надаючи можливість побудови імітаційних моделей технічних об'єктів (зокрема, електромеханічних систем) у мобільному Web-браузері. Поточна мета проєкту Xcos on Cloud (колишній Xcos on Web (Modlo \& Semerikov, 2018)) відтворити повнофункціональну версію Scilab Xcos 3 доступом через мобільний Web-браузер (Xcos, 2019). Реалізація у Xcos on Cloud повної функціональності Scilab Xcos створює умови для переходу у навчанні бакалаврів електромеханіки моделювання технічних об'єктів до використання мобільних інтернет-пристроїв. Схожі можливості надає повна віртуалізація Scilab on rollApp (Scilab Online, 2018).

Висновки і перспективи подальших досліджень. Таким чином, у процесі формування загальнопрофесійної компетентності бакалавра електромеханіки в моделюванні технічних об'єктів доцільно використовувати відповідне програмне забезпечення мобільних інтернетпристроїв, а саме: хмаро орієнтовані табличні процесори як засоби моделювання (включно із нейромережевим); системи візуального моделювання як засоби структурного моделювання технічних об'єктів; мобільні комп'ютерні математичні системи, що використовується на всіх етапах моделювання; мобільні комунікаційні засоби для організації спільної діяльності з моделювання.

Перспективним напрямом подальших досліджень постає проблема використання мобільних інтернет-пристроїв у формуванні компетенції із розв'язання професійних задач засобами інформаційнокомунікаційних технологій.

\section{Список використаних джерел}

Kanivets, O. V., Kanivets, I. M., Kononets, N. V., Gorda, T. M. \& Shmeltser, E. O. (2020). Augmented reality mobile application developments for help to performance tasks from projection drawing, CEUR Workshop Proceedings, 2547, 262-273.

Markova, O., Semerikov, S. \& Popel, M. (2018). CoCalc as a Learning Tool for Neural Network Simulation in the Special Course «Foundations of Mathematic Informatics», CEUR Workshop Proceedings, 2104, 338403.

Modlo, Ye. O., $\quad$ Semerikov, S. O., $\quad$ Bondarevskyi, S. L., $\quad$ Tolmachev, S. T., Markova, O. M. \& Nechypurenko, P. P. (2020). Methods of using 
mobile Internet devices in the formation of the general scientific component of bachelor in electromechanics competency in modeling of technical objects, CEUR Workshop Proceedings, 2547, 217-240.

Modlo, Ye. O., Semerikov, S. O., Nechypurenko, P. P., Bondarevskyi, S. L., Bondarevska, O. M. \& Tolmachev, S. T. (2019). The use of mobile Internet devices in the formation of ICT component of bachelors in electromechanics competency in modeling of technical objects, CEUR Workshop Proceedings, 2433, 413-428.

Modlo, Ye. O., Semerikov, S. O. \& Shmeltzer, E. O. (2018). Modernization of Professional Training of Electromechanics Bachelors: ICT-based Competence Approach, CEUR Workshop Proceedings, 2257, 148172.

Modlo, Ye. O. \& Semerikov, S. O. (2018). Xcos on Web as a promising learning tool for Bachelor's of Electromechanics modeling of technical objects, CEUR Workshop Proceedings, 2168, 34-41.

Модло, Є. О. (2015). До визначення поняття мобільного Інтернет-пристрою. Збірник матеріалів III Всеукраїнської науково-практичної конференції молодих учених «Наукова молодь-2015». 37-38. Київ : IITЗН НАПН України. URL : http://lib.iitta.gov.ua/704728

Модло, Є. О. \& Семеріков, С. О. (2014). Розробка фрільтру SageMath для Moodle, Новітні комп'ютерні технології, том XII, 233-243.

Popel, M. V., Shokalyuk, S. V., Shyshkina, M. P. (2017). The Learning Technique of the SageMathCloud Use for Students Collaboration Support, CEUR Workshop Proceedings, 1844, 327-339.

Rassovytska, M. V. \& Striuk, A. M. (2017). Mechanical Engineers' Training in Using Cloud and Mobile Services in Professional Activity, CEUR Workshop Proceedings, 1844, 348-359.

Site of «SageMathCell». URL : http://sagecell.sagemath.org

Site of "Scilab». (2019).

URL :

https://uk. wikipedia.org/w/index.php?title=Scilab\&oldid=24491902.

Site of "Scilab is recognized as having educational value by the French Department of Education». (2011). Rocquencourt, July $26^{\text {th }} 2011$. Online. URL : https://www.scilab.org/content/download/514/4351/file/CP_Scilab_26 072011_eng.pdf

Site of «Scilab Online». (2018). URL : https://www.rollapp.com/app/scilab Соболь, И. М. (1968). Метод Монте-Карло. Москва : Наука.

Tkachuk, V. V., Shchokin, V. P. \&Tron, V. V. (2018). The Model of Use of Mobile Information and Communication Technologies in Learning Computer Sciences to Future Professionals in Engineering Pedagogy, CEUR Workshop Proceedings, 2257, 103-111.

Site of «Web application - Scilab.io». (2016). URL: https://scilab.io/services/development/web-application

Site of «Xcos». (2019). URL : http://xcos.fossee.in 


\section{References (translated and transliterated)}

Kanivets, O. V., Kanivets, I. M., Kononets, N. V., Gorda T. M. \& Shmeltser, E. O. (2020). Augmented reality mobile application developments for help to performance tasks from projection drawing, CEUR Workshop Proceedings, 2547, 262-273 [in English].

Markova, O., Semerikov, S. \& Popel, M. (2018). CoCalc as a Learning Tool for Neural Network Simulation in the Special Course «Foundations of Mathematic Informatics», CEUR Workshop Proceedings, 2104, 338-403 [in English].

Modlo, Ye. O., $\quad$ Semerikov, S. O., $\quad$ Bondarevskyi, S. L., $\quad$ Tolmachev, S. T., Markova, O. M. \& Nechypurenko, P. P. (2020). Methods of using mobile Internet devices in the formation of the general scientific component of bachelor in electromechanics competency in modeling of technical objects, CEUR Workshop Proceedings, 2547, 217-240 [in English].

Modlo, Ye. O., $\quad$ Semerikov, S. O., $\quad$ Nechypurenko, P. P., $\quad$ Bondarevskyi, S. L., Bondarevska, O. M. \& Tolmachev, S. T. (2019). The use of mobile Internet devices in the formation of ICT component of bachelors in electromechanics competency in modeling of technical objects, CEUR Workshop Proceedings, 2433, 413-428 [in English].

Modlo, Ye. O., Semerikov, S. O. \& Shmeltzer, E. O. (2018). Modernization of Professional Training of Electromechanics Bachelors: ICT-based Competence Approach, CEUR Workshop Proceedings, 2257, 148-172 [in English].

Modlo, Ye. O. \& Semerikov, S. O. (2018). Xcos on Web as a promising learning tool for Bachelor's of Electromechanics modeling of technical objects, CEUR Workshop Proceedings, 2168, 34-41 [in English].

Modlo, Ye. O. (2015). Do vyznachennja ponjattja mobiljnogho Internet-prystroju [To the definition of a mobile Internet device]. Zbirnyk materialiv III Vseukrainskoi naukovo-praktychnoi konferentsii molodykh uchenykh "Naukova molod-2015» - Proceedings of the Third All-Ukrainian scientific conference of young scientists "Scientific youth-2015», (pp. 3738). Kyiv: IITLT of the NAES of Ukraine. Retrieved from http://lib.iitta.gov.ua/704728 [in Ukrainian].

Modlo, Ye. O. \& Semerikov, S. O. (2014). Rozrobka filjtru SageMath dlja Moodle [Development of SageMath filter for Moodle]. Novitni komp'juterni tekhnologhiji - New computer technology, Vol XII, 233-243 [in Ukrainian].

Popel, M. V., Shokalyuk, S. V., Shyshkina, M. P. (2017). The Learning Technique of the SageMathCloud Use for Students Collaboration Support, CEUR Workshop Proceedings, 1844, $327-339$ [in English].

Rassovytska, M. V. \& Striuk, A. M. (2017). Mechanical Engineers' Training in Using Cloud and Mobile Services in Professional Activity, CEUR Workshop Proceedings, 1844, 348-359 [in English].

Site of «SageMathCell». URL : http://sagecell.sagemath.org [in English].

Site of «Scilab». (2019). Online. URL: https://uk. wikipedia.org/w/index.php?title=Scilab\&oldid=24491902 [in English]. 
Site of «Scilab is recognized as having educational value by the French Department of Education». (2011). Rocquencourt, July 26 $6^{\text {th }}$ 2011. Online. URL: https://www.scilab.org/content/download/514/4351/file/CP_Scilab_26072 011_eng.pdf [in English].

Site of «Scilab Online». (2018). URL: https://www.rollapp.com/app/scilab [in English].

Sobolj, Y. M. (1968). Metod Monte-Karlo [Monte Carlo method]. Moskva : Nauka [in Russian].

Tkachuk, V. V., Shchokin, V. P. \& Tron, V. V. (2018). The Model of Use of Mobile Information and Communication Technologies in Learning Computer Sciences to Future Professionals in Engineering Pedagogy, CEUR Workshop Proceedings, 2257, 103-111 [in English].

Site of «Web application - Scilab.io». (2016). URL: https://scilab.io/services/development/web-application [in English].

Site of «Xcos». (2019). URL : http://xcos.fossee.in [in English].

удк $378 ; 37.003 .42$

DOI: https://doi.org/10.35387/od.2(18).2020.115-122

Товканець Ганна Василівна - доктор педагогічних наук, профресор, завідувач кафедри теорії та методики початкової освіти Мукачівського державного університету

ORCID ID https://orcid.org/0000-0002-6191-9569

E-mail: tovkanec2017@gmail.com

\section{ПІДГОТОВКА МАЙБУТНІХ ПЕДАГОГІВ ДО ВИХОВАННЯ ДІТЕЙ-СИРІТ В УМОВАХ СОЦІАЛЬНИХ ТРАНСФОРМАЦІЙ}

Анотація. Оглядову публікацію присвячено проблемі підготовки майбутніх педагогів до виховання дітей-сиріт в умовах соціальних трансорормацій. В статті обгрунтовано напрями підготовки майбутніх педагогів до виховання дітей-сиріт в умовах соціальних трансформацій. Визначено готовність майбутніх педагогів до роботи з дітьмисиротами як особистісне утворення, що передбачає наявність професійно важливих якостей та характеризується спрямованістю на успішну взаємодію з вихованцями. Підкреслено, що напрямами профресійної підготовки майбутніх педагогів в умовах соціальних трансфрормацій $є$ : акцент на розробку програм соціального виховання $в$ освітніх навчальних закладах, врахування активно-діяльнісної природи дитини-сироти, ї̈ прагнення до участі в ціннісно-значимій, креативнодослідній, індивідуально-комфортній життєдіяльності; спрямування соціально-педагогічної діяльності на формування адекватних иіннісних орієнтацій, соціального досвіду, установок на досягнення соціальнопсихологічного комфорту; вивчення законодавчо-нормативного забезпечення; впровадження конструктивних ідей зарубіжного досвіду 